\title{
Opposing effects of input control and clan control for sellers on e-marketplace platforms
}

\author{
Evgheni Croitor $^{1}$ (D) $\cdot$ Dominick Werner $^{1} \cdot$ Martin Adam $^{1} \cdot$ Alexander Benlian $^{1}$
}

Received: 4 December 2020 / Accepted: 9 February 2021 / Published online: 2 March 2021

(C) The Author(s) 2021

\begin{abstract}
E-marketplace platforms focus on attracting and retaining sellers to secure the platform's long-term viability and success. Although sellers' behavioral intentions have been linked to control modes deployed on e-marketplace platforms, little is known about how and why perceptions of input control and clan control affect sellers' crucial behavioral outcomes. Drawing on IS control literature, we conducted two online surveys with sellers on Amazon $(n=286)$ and Etsy $(n=185)$. Our results revealed that perceived input control had a negative effect on sellers' perceived usefulness, satisfaction, and continuance intentions, whereas positive effects were observed with perceived clan control. In addition, we find that intrinsic motivation mediates the observed direct effects. Our study contributes to the literature by introducing control modes in the context of e-marketplace platforms and examining the effects of input control and clan control on sellers' beliefs, attitudes, and behavioral intentions. Furthermore, our study has important practical implications for platform providers in how to apply different control mechanisms and increase complementors' willingness to keep contributing to e-marketplace platforms, thereby nurturing platform health and sustainability.
\end{abstract}

Keywords Input Control · Clan Control · E-Marketplace Platforms · Intrinsic Motivation · Continuance Intention

JEL classification D4 $\cdot \mathrm{O} 3$

\section{Introduction}

Over the past decade, digital platforms (e.g., Amazon, GoFundMe, Airbnb, and Android) have emerged as some of the most successful business models and venues of innovation (de Reuver et al. 2018; Tan et al. 2015), fundamentally

Responsible Editor: Marianna Sigala

Evgheni Croitor

croitor@ise.tu-darmstadt.de

Dominick Werner

werner@ise.tu-darmstadt.de

Martin Adam

adam@ise.tu-darmstadt.de

Alexander Benlian

benlian@ise.tu-darmstadt.de

1 Information Systems and E-Services, Technical University of Darmstadt, Hochschulstrasse, 1, 64293 Darmstadt, Germany changing the way products and services are created, distributed, and maintained (Constantinides et al. 2018; de Reuver et al. 2018). Hereby, the platforms' economic viability and success primarily results from complementors (e.g., sellers, campaign organizers, developers, and accommodation owners) and their provided complements (e.g., products, crowdfunding campaigns, accommodations, and mobile apps) (Boudreau 2012; Huang et al. 2017; Thies et al. 2016). In this regard, attracting complementors to a digital platform is considered important due to cross-side network effects: The higher the number of complementors offering complements on a platform, the higher the number of end-users who access the platform, thereby increasing the value of the platform as a whole (Galbreth et al. 2005; Katz and Shapiro 1985). For example, on Etsy, an e-marketplace platform for handcrafted and vintage products, between 2013 and 2019 the number of sellers (i.e., complementors on e-marketplace platforms) more than doubled from 1.1 million to 2.7 million active sellers, while during the same period, the number of buyers (i.e., end-users on e-marketplace platforms) more than tripled from 14.0 million to 45.7 million active buyers (Etsy 2019). 
As the number of complementors and offered complements grow, platform providers need to exercise control to align their interests and strategies with those of the complementors (Saunders et al. 2020). To manage complementors and their complements, platform providers draw on control modes (i.e., the set of mechanisms to control complementors and their complements on digital platforms) (Tiwana et al. 2010). IS scholars started to investigate control modes on digital platforms with a focus on contexts such as mobile apps (Croitor and Benlian 2019; Goldbach et al. 2018), web browsers (Croitor et al. 2020; Tiwana 2015), and crowdfunding (Thies et al. 2018; Wessel et al. 2017).

Yet surprisingly, IS research has hitherto neglected the key role of control modes on e-marketplace platforms, which offer a unique and intriguing context for two main reasons: First, the prevalence and size of e-marketplace platforms have led to a tremendous relevance in the digital era ( $\mathrm{Li}$ et al. 2019; Sun et al. 2020). Part of their central role is attributed to transactions on e-marketplace platforms typically being of higher value than transactions on other digital platforms such as for mobile apps and web browser, where many complements are offered free of charge. As such, stakes are high for buyers on e-marketplace platforms, thereby making effective control mechanisms ever more important to ensure adequate quality of complements. Second, e-marketplace platforms offer largely physical goods as complements, compared to primarily digital complements on mobile apps, web browser and crowdfunding platforms. Consequently, platform providers need to control complementors more intensely to ensure high complement quality immediately upon publication, as subsequent updates for physical (vs. digital) goods are much harder to provide. In addition, for platform providers to evaluate a complement, access to the complement's information is required (Kirsch 1996), which is more difficult in case of physical instead of digital goods, forcing platform providers to change their control implementation (e.g., the quality of a complement cannot be reviewed in an automatized, instantaneous review process as is commonplace for mobile apps and web browser extensions). Taken together, control on emarketplace platforms differs in its role, importance and implementation from previously investigated platform contexts and thus requires a more nuanced understanding by IS research.

In the context of e-marketplace platforms, two control modes are particularly important for platform providers and have been highlighted in previous calls for research (Goldbach et al. 2018): input control and clan control (Boon et al. 2015; Tiwana 2015; Zifla and Wattal 2019). Input control can be described as the set of mechanisms used by the platform provider to screen and sort out sellers and their products before entering the e-marketplace platform (Croitor and Benlian 2019; Tiwana 2015). Consider, for example, the input control on the Etsy platform: Sellers have to (1) sell products that are made or designed only by them, (2) describe every person involved in the making of a product, and (3) use their own photographs of these products. Input control is especially relevant in loosely coupled organizational structures, such as e-marketplace platforms, where it is less viable for platform providers to control sellers' product creation process (Ouchi 1979; Tiwana 2015). Clan control, on the other hand, refers to the set of mechanisms used by the platform provider to establish shared norms, values and strong affiliation feelings among complementors (Ouchi 1979, 1980). For example, to reinforce seller participation, knowledge sharing and content curation, Etsy provides IT-features for sellers to give feedback to other sellers, to promote other sellers' products and to join seller groups (Zifla and Wattal 2019). Clan control is especially relevant on digital platforms that strive to build and nurture communities, such as e-marketplace platforms, where sellers rely on long-term relationships (Kirsch et al. 2002; Kohli and Kettinger 2004). For platform providers who are trying to attract and motivate sellers to contribute to their emarketplace platform, it is important to understand whether and how input and clan control influence seller participation: Will input and clan control undermine or amplify sellers' continuance intentions and do they have similar or opposing effects?

Furthermore, although previous studies have investigated the effects of control modes on complementors' behavioral intentions on digital platforms, research has provided little explanation about why input control and clan control affect complementors' behavioral intentions. In this regard, a factor repeatedly mentioned to relate to sellers' intentions to continue selling products is their motivation (Sun 2010). Given that, in the context of e-marketplace platforms, sellers are afforded fairly great freedom to choose what and how much they offer on which platform, sellers' continuance intentions are likely to be driven primarily by their intrinsic motivation. Although intrinsic motivation is well studied as an important factor influencing sellers' beliefs, attitudes and behavioral intentions on e-marketplace platforms (Sun 2010), research considering its potentially mediating role to explain the mechanism of input control and clan control is still absent.

In summary, we lack important knowledge on how perceptions of input control and clan control affect sellers' beliefs (i.e., perceived usefulness), attitudes (i.e., satisfaction) and behavioral intentions (i.e., continuance intentions) on emarketplace platforms. Moreover, our understanding is incomplete as to why the effects of these control modes unfold and to what extent intrinsic motivation serves as a mediator. As such, we set out to investigate our research question:

RQ: How and why do perceptions of input control and clan control affect sellers' beliefs, attitudes and behavioral intentions on e-marketplace platforms? 
To answer our research question, we draw on IS control literature and conducted two online surveys with sellers on the e-marketplace platforms Amazon and Etsy, which both apply input control and clan control and therefore offer a highly suitable context for our research. The results of our empirical study show that sellers' perceptions of input control and clan control have opposing effects on sellers' beliefs, attitudes, and behavioral intentions and that these effects are mediated by intrinsic motivation. Furthermore, by testing our hypotheses on two platforms, we were able to ensure that our results are robust across platforms of different sizes and different product portfolios.

Our study makes several contributions to research on platform control. First, by studying control modes on emarketplace platforms, our work extends the research scope of increasing literature on platform control (Croitor et al. 2020; Goldbach et al. 2018; Wessel et al. 2017) by the unique and thus far disregarded context of e-marketplace platforms. Therefore, our work advances the literature by empirically testing the influence of control modes on complementors' crucial behavioral outcomes on digital platforms in general and e-marketplaces in particular. Appendix Table 1 presents a list of previous studies of control modes on digital platforms and shows how our study extends prior research. Second, by studying effects of both input control and clan control on complementors' beliefs, attitudes, and behavioral intentions, our study extends prior research on platform control that has examined the effects of input control and clan control separately. Third, we shed light on the mechanisms through which the effects of input control and clan control affect complementors' beliefs, attitudes, and behavioral intentions by revealing intrinsic motivation as a mediator for both control modes. We also provide practical implications that are critical for platform providers to develop different control mechanisms, which can increase complementors' willingness to stay on and keep contributing to e-marketplace platforms, thereby nurturing platform health and sustainability.

\section{Theoretical background}

\section{Control on E-marketplace platforms}

Prior IS and strategic management research has defined and conceptualized e-marketplace platforms as infrastructure that mediates interactions between sellers and buyers (Eisenmann et al. 2011; Foerderer et al. 2018; McIntyre and Srinivasan 2017). Unlike intermediaries on traditional markets (e.g., retail stores), platform providers of e-marketplace platforms do not take ownership of the products and services transacted (Hagiu and Yoffie 2009). Instead, e-marketplace platforms generate value for sellers and buyers by facilitating their transactions with one another, hence improving correspondence between supply and demand and thus enhancing market efficiency (Hagiu 2006).

One important objective of platform providers of emarketplace platforms is to increase their base of sellers, which consequently attracts more buyers due to cross-side network effects (Galbreth et al. 2005; Katz and Shapiro 1985; Thies et al. 2018). However, growing a large group of sellers offering a broad variety of products also creates risks, as products that exhibit low quality or that are a misfit to the platform may harm the quality and reputation of the platform (Tiwana et al. 2010; Wareham et al. 2014). Therefore, a major challenge for platform providers on such e-marketplace platforms refers to governance in general (Song et al. 2018) and control over sellers' and their products in particular (Tiwana et al. 2010). In the context of e-marketplace platforms, control refers to means through which platform providers ensure that sellers and their products are aligned with what is in the interests of the emarketplace platform (Wiener et al. 2019). IS control literature draws a fundamental distinction between control modes, which can be divided into formal and informal types of control (Kirsch 1997; Ouchi 1979; Wiener et al. 2016). Formal control modes (i.e., input control, behavior control, and outcome control) are enforced by platform providers through specification and evaluation (Cardinal 2001; Cardinal et al. 2004). In contrast, informal control modes (i.e., self control and clan control) are built on meanings of self-regulation or shared norms and values of groups or individuals (Wiener et al. 2016). In this study, we investigate input control and clan control, as both control modes have been emphasized to increase in importance for emarketplace platforms (Boon et al. 2015; Tiwana 2015; Zifla and Wattal 2019).

Input control refers to platform providers using gatekeeping and screening procedures to decide which sellers and products are allowed to enter the respective platform (Croitor and Benlian 2019). Recently, IS research has paid more attention to input control in a broad context of platforms: Within crowdfunding, relaxing input control has been linked to decreasing quality and increasing quantity of submitted campaigns (Thies et al. 2018; Wessel et al. 2017), whereas in the context of web browsers (Croitor et al. 2020; Tiwana 2015) and mobile applications (Croitor and Benlian 2019) developers' perceptions of higher input control negatively impacted their continuance intentions. Input control becomes especially relevant in loosely coupled organizational structures, such as emarketplace platforms, where it is less viable for platform providers to control sellers' product creation process (Ouchi 1979; Tiwana 2015). Within the context of e-marketplace platforms, platform providers exercise input control by setting a range of requirements: Amazon, for example, requires its sellers to ensure legality of the products, to adhere to predefined product categories, and to provide pictures that exceed a minimum resolution (Amazon 2020). Another example, the e-marketplace platform Etsy, asks its sellers to exclusively sell products that 
are made or designed by them, to describe every person involved in the making of a product, and to use their own photographs of these products (Etsy 2020).

The second control mode investigated in this study, clan control, takes an informal approach to direct, influence or regulate sellers to achieve e-marketplace platform goals by drawing on sellers as a clan. A clan is a culturally homogeneous group whose members share common beliefs, norms and values (Ouchi and Price 1978). Unlike input control, which relies on formal power or organizational authority, exercising clan control builds on regular interactions and information sharing among sellers to spread these shared beliefs, norms and values (Chua et al. 2012). IS research investigating clan control on platforms thus far found positive effects on product performance as well as success (Goldbach and Benlian 2015a), and found indication that perceived clan control increases sellers' continuance intention (Goldbach and Benlian 2015b). Clan control is especially relevant for groups, such as sellers on e-marketplace platforms, when outcomes (e.g., product sales) can vary substantially and when behavior (e.g., how sellers should create their products) is hard to specify (Kirsch 2004; Kohli and Kettinger 2004). E-marketplace platforms harness clan control to reinforce seller participation, knowledge sharing and content curation: The platform Etsy, for example, encourages its sellers to give feedback to other sellers, to select their favorite products of other sellers and to join seller groups (Zifla and Wattal 2019).

Although prior studies have investigated effects of input control and clan control in different platform contexts, the effects of control modes on e-marketplace platforms have been largely overlooked. Furthermore, our understanding of the mechanism of the combination of input control and clan control is still limited, as previous research investigated the effects of input control or clan control separately. To understand why perceptions of both control modes affect sellers' perceived usefulness, satisfaction, and continuance intentions, we examine how control influences sellers' intrinsic motivation as an important antecedent to sellers' behavioral intentions (Sun 2010).

\section{Sellers' intrinsic motivation}

Intrinsic motivation refers to individuals' motivation to complete a task or perform an action out of own interest, enjoyment and for the sake of the activity itself (Deci and Ryan 1985). Intrinsic motivation is explained by selfdetermination theory, which considers individuals' fundamental needs for autonomy, relatedness and competence (Gagné and Deci 2005; Ryan and Deci 2000; Sheldon Kennon et al. 2003). The need for autonomy is an individual's innate psychological desire to be free to choose their course of action. Any restriction to individuals' autonomy, for example through formal requirements, reduces individuals' intrinsic motivation (Thatcher et al. 2012). The need for relatedness refers to individuals' desire to experience a sense of belonging or connectedness to other individuals. Any measures promoting a sense of relatedness, for example by communicating shared norms and values, increase individuals' intrinsic motivation (Sheldon Kennon et al. 2003). Finally, the need for competence is individuals' innate psychological desire of being effective in dealing with the environment in which a person finds oneself.

Previous IS studies investigated the influence of intrinsic motivation as a driver of individuals' behavior on platforms in various contexts, such as completing tasks on crowdsourcing platforms (Kaufmann et al. 2011), sticking with e-learning platforms (Ho 2010), competing in co-creation platforms (Zheng et al. 2011), developing apps for social software platforms (Hilkert et al. 2010) and sharing knowledge in enterprise social media platforms (Rode 2016). Moreover, first studies have linked intrinsic motivation to platform control: In the context of mobile application platforms, developers' intrinsic motivation has been identified to explain why informal control modes increase application quality (Goldbach and Benlian 2015b). Nevertheless, these findings are limited in that they cannot explain the mechanisms when both formal and informal control modes are employed simultaneously. As such, research has yet to investigate whether intrinsic motivation can explain why perceptions of both input control and clan control affect sellers' beliefs (i.e., perceived usefulness), attitudes (i.e., satisfaction) and behavioral intentions (i.e., continuance intentions) on e-marketplace platforms. Given that emarketplace platforms benefit from sellers who are eager to invest their time and effort into selling on the platform, we focus on the role of sellers' intrinsic motivation in order to analyze the effects between perceptions of control modes and sellers' crucial behavioral outcomes.

\section{Research model and hypothesis development}

In this section, we develop our research model as illustrated in Fig. 1. Following guidelines by Hong et al. (2014) on developing context-specific models, we adopted the established model of IS continuance by Bhattacherjee (2001). This model is particularly suitable for our study for two reasons: First, in line with our objective of investigating sellers' long-term intentions, the IS continuance model captures sellers' postadoption behaviors (i.e., continued use rather than first-time use of the e-marketplace platform). Second, the model improves our ability to explain sellers' continuance intentions based on both beliefs (i.e., perceived usefulness) and attitudes (i.e., satisfaction) of sellers.

We propose that perceived input control has a negative effect on sellers' intrinsic motivation (H1), whereas perceived clan control is expected to exert a positive effect on sellers' 


\section{Formal and Informal} Control Modes

\section{Beliefs, Attitudes, and Behavioral Intentions}
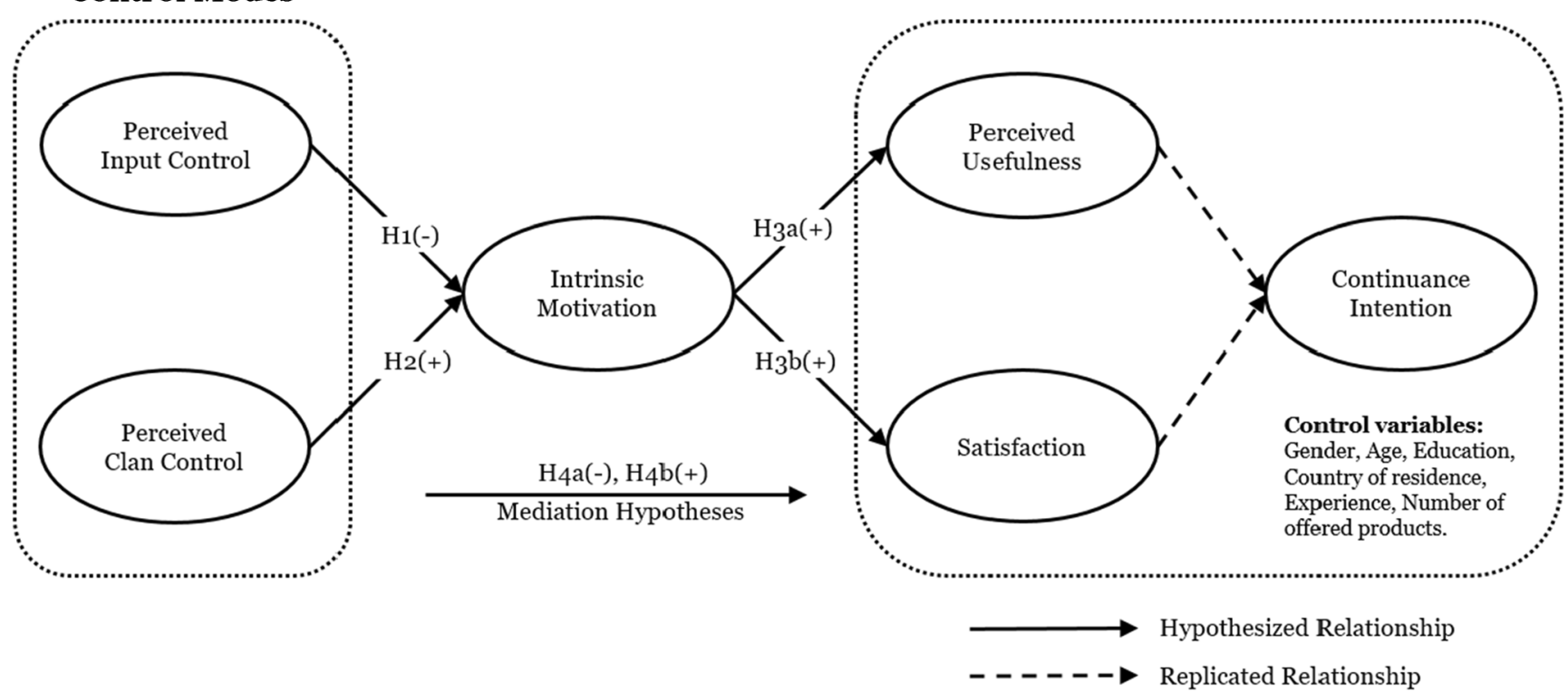

Fig. 1 Research model

intrinsic motivation (H2). Furthermore, we propose that sellers' intrinsic motivation affects sellers' beliefs (i.e., perceived usefulness, H3a) and attitudes (i.e., satisfaction, $\mathrm{H} 3 \mathrm{~b}$ ). Consequently, we argue that intrinsic motivation mediates the effect of perceptions of both control modes on sellers' beliefs (i.e., perceived usefulness) and attitudes (i.e., satisfaction) and subsequently behavioral intentions (i.e., continuance intention, H4a,b). We do not hypothesize for any effect between perceived usefulness, satisfaction and continuance intention, as prior IS research has consistently shown that individuals' intentions to contribute to a platform is affected by their satisfaction with and perceived usefulness of the platform (e.g., Croitor et al. 2020; Kim et al. 2016).

\section{Hypothesis development}

To first derive how perceived input control and perceived clan control affect sellers' intrinsic motivation, we consider how intrinsic motivation emerges. According to self-determination theory, intrinsic motivation is the result of the fulfilment of the three psychological needs autonomy, competence and relatedness (Gagné and Deci 2005; Ryan and Deci 2000; Sheldon Kennon et al. 2003). In the case of perceived input control, we focus on sellers' sense of autonomy, which refers to whether individuals feel that they define and control the manner in which tasks are executed (Hall 1968). Autonomy is particularly important to individuals when tasks require specialized knowledge (e.g., managing a portfolio of products) and individuals believe they are the only ones qualified to decide how their work should be performed. Any restriction of individuals' autonomy is expected to impact their intrinsic motivation (Thatcher et al. 2012) of performing a task.

Linking to individuals' autonomy, perceived input control in the context of e-marketplace platforms primarily describes sellers' perceptions of barriers complicating the release of new products on the platform through gatekeeping and screening procedures. If sellers are restricted in their freedom to choose which products they are allowed to sell, part of their psychological need for autonomy is unmet. In turn, their intrinsic motivation is impaired. The higher the level of perceived input control, the less autonomous will sellers feel and the less will they experience intrinsic motivation. Therefore, we hypothesize:

H1: Perceived input control has a negative effect on sellers' intrinsic motivation.

Aside from autonomy, individuals' experience of intrinsic motivation is also determined by their need for relatedness, which describes the desire to experience a sense of belonging or connectedness to other individuals (Ryan and Deci 2000). To this end, the perception of clan control is particularly relevant. Clan control is based on communicating shared beliefs, norms and values and on reducing differences in individuals' views (Chua et al. 2012; Kirsch 1997). Clan control is achieved when individuals internalize the common goals and strategies exchanged through regular interactions, thereby becoming part of the clan (Kirsch et al. 2002). Members of a clan typically share knowledge and discuss issues openly, affording each member the possibility to express their competence and share their expertise (Gopal and Gosain 2010). 
Additionally, working with individuals with similar mindsets and goals fosters commitment to a group and a homelike feeling (Das and Teng 2001; Ouchi 1980).

Applied to the context of e-marketplace platforms, the perception of clan control based on common beliefs, norms and values between sellers facilitates a sense of relatedness and belonging to the seller community. According to selfdetermination theory, satisfying sellers' need for relatedness increases sellers' intrinsic motivation of selling products. Therefore, we hypothesize:

H2: Perceived clan control has a positive effect on sellers' intrinsic motivation.

We consider intrinsic motivation to link to the antecedents of the IS continuance model. We start with the link to sellers' beliefs in the form of perceived usefulness. We refer to perceived usefulness as the extent to which a platform is perceived as useful by sellers for their selling performance (Davis 1989). Previous studies indicate that perceived usefulness is subject to individuals' intrinsic motivation: Intrinsically motivated individuals spend more time on tasks and exhibit increased deliberation and thoroughness of cognitive processing (Bagozzi et al. 1999; Mano 1992). In turn, this higher level of involvement enhances individuals' perceptions of usefulness (Batra and Ray 1986; Venkatesh et al. 2002).

Applied to the context of e-marketplace platforms, if sellers are intrinsically motivated and enjoy selling products on the platform, they are more likely to perceive the platform as useful for selling their products. This logic is supported by previous studies indicating that sellers' perceived enjoyment increases their perceptions of usefulness of online markets (Sun 2010). Thus, we conclude:

H3a: Intrinsic motivation has a positive effect on sellers' perceived usefulness.

We furthermore contend that intrinsic motivation influences sellers' satisfaction. Generally, satisfaction describes individuals' emotional reaction to their experiences (Igbaria and Chidambaram 1997). According to Bhattacherjee (2001), satisfaction with an IS system results from the repeated use of the system. The assessment of the system's performance in comparison to the individuals' expectations then determines the level of satisfaction experienced. This assessment is influenced by individuals' intrinsic motivation: As individuals experiencing higher levels of intrinsic motivation strive to complete a task out of own interest and for the sake of the activity itself (Deci and Ryan 1985), they are likely to engage more intensely with the IS system and to thus harness its capabilities to a greater extent. Together with the positive affective state induced by intrinsic motivation, individuals therefore evaluate the system's performance more positively, leading to greater satisfaction.

In the context of e-marketplace platforms, where sellers' satisfaction refers to their evaluation and affective response to the overall experience with the platform (Oliver 1980), we therefore expect that sellers who are intrinsically motivated will experience a greater sense of satisfaction of using the emarketplace platform to sell their products. This is further corroborated by previous research in organizational contexts implying that workers' intrinsic motivation drives feelings of job satisfaction (Ambrose and Kulik 1999; Dinger et al. 2015). Therefore, we conclude:

H3b: Intrinsic motivation has a positive effect on sellers' satisfaction.

In line with the arguments presented above, we believe that sellers perceiving high input control experience lower perceived usefulness as well as lower satisfaction, driven by reduced intrinsic motivation. Furthermore, we believe that sellers perceiving high clan control experience higher perceived usefulness as well as higher satisfaction, driven by increased intrinsic motivation. Considering that the IS continuance model proposes perceived usefulness to improve satisfaction and that both perceived usefulness and satisfaction influence continuance intentions, we thus conclude:

H4a: Intrinsic motivation mediates the effect of perceived input control on sellers' perceived usefulness, satisfaction and subsequently continuance intentions.

$\mathrm{H} 4 \mathrm{~b}$ : Intrinsic motivation mediates the effect of perceived clan control on sellers' perceived usefulness, satisfaction and subsequently continuance intentions.

\section{Methodology}

To empirically validate our research model, we conducted online surveys with sellers of two popular e-marketplace platforms. We elaborate on details of the empirical setting, the data collection procedure, the construct operationalization and the assessment of common method variance in each of the following subsections.

\section{Empirical setting}

We decided to focus our empirical setting on Amazon and Etsy, which have similar institutional structures. Amazon, the largest U.S. online retailer, allows third-party sellers to sell products on its e-marketplace platform. As such, the platform offers a wide range of mass products. In 
contrast, Etsy facilitates the sale of unique handcrafted and vintage products. Its focus on cultural goods is reflected in its product categories that range from art and collectibles over jewelry and accessories to clothing and shoes. Etsy launched in 2005 in the United States and is continuously growing ever since (Etsy 2019).

Three reasons informed our choice of Amazon and Etsy to study the effects of control modes on sellers' continuance intentions: First, Amazon and Etsy are typical and thus representative e-marketplace platforms that are accessible to the public and that facilitate sales by connecting sellers and buyers online. Second, Amazon and Etsy apply input control mechanisms on their e-marketplace platforms. Amazon requires its sellers to ensure legality of the products, to adhere to predefined product categories and to provide pictures that exceed a minimum resolution (Amazon 2020). Etsy, on the other hand, requires sellers to only offer products they made or designed themselves, to describe every person involved in the making of a product and to use their own photographs. Only if all requirements are met are sellers allowed to distribute their products. Third, Amazon and Etsy exercise clan control. Amazon provides IT-features that enable sellers to write blog posts for other sellers. Etsy, on the other hand, provides IT-features that enable sellers to give feedback to other sellers, to promote other sellers' products, and to join seller groups. These features help sellers cultivate relationships with peers in order to gain status in the e-marketplace and become successful in the long term (Bourdieu and Nice 1980). Fourth, Amazon with 2.2. million active sellers (MarketplacePulse 2020) and Etsy with 2.7 million active sellers (Etsy 2019) rank among the largest e-marketplace platforms worldwide (Digitalcommerce 2020). As such, findings derived from Amazon and Etsy concern a large audience of sellers on emarketplace platforms. Lastly, testing our hypotheses on two platforms allows us to see whether our findings are robust across platforms of different sizes and different product portfolio focus. In conclusion, Amazon and Etsy provide a suitable context for examining the relationships between perceived input control as well as perceived clan control and sellers' continuance intentions on e-marketplace platforms.

\section{Data collection}

To test our hypotheses, we developed and conducted two online surveys addressing sellers on Amazon and Etsy over a period of 3 months. We used chat forums and social media to contact sellers who had experience with selling products on one of the platforms. As an incentive, we assured to fund the planting of a tree for every completed survey. In total, 300 sellers on Amazon and 210 sellers on Etsy completed the survey. We dropped 39 participants due to an implausibly short response time or an incorrect answer to an attention check question. This removal resulted in our final sample of 286 respondents from Amazon and 185 respondents from Etsy. In the Amazon sample, sellers were largely male $(74.1 \%)$. In contrast, sellers in Etsy sample were largely female $(82.2 \%)$. The largest fractions of our respondents lived in Germany and the United States, followed by the United Kingdom. Sample demographics are shown in Appendix Table 2.

\section{Construct operationalization}

To design our survey, we screened policies and terms and conditions of various e-marketplace platforms for different forms of control. Based on these results, we adapted survey items using established measures from existing scales in platform literature (see Appendix Table 3). In line with previous studies on e-marketplace platforms (e.g., Croitor et al. 2020; Goldbach and Benlian 2015b; Goldbach et al. 2018), we assessed perceived input control (Croitor and Benlian 2019), perceived clan control (Kirsch et al. 2002) and intrinsic motivation (Deci and Ryan 2002). Additionally, we measured the three constructs of the IS continuance model: perceived usefulness (Agarwal and Karahanna 2000), satisfaction (Bhattacherjee 2001) and continuance intention (Bhattacherjee 2001). All constructs in our survey were measured reflectively with items measured on a sevenpoint Likert-type scale, ranging from 1 (strongly disagree) to 7 (strongly agree). In addition, we measured control variables in the prediction of the dependent variables. We controlled the dependent variables for gender, age, education, country of residence and experience in years and number of offered products.

\section{Common method variance}

We performed several steps to reduce any common method bias that might arise because of the use of a single data source (Podsakoff et al. 2003). First, during the design of the study's procedures, we strove to minimize method bias by protecting respondents' anonymity and reducing evaluation apprehension: We informed all respondents that their answers would be anonymous, that there were no right or wrong answers, and that responses would be used solely for research purposes. Second, we applied caution in the selection and phrasing of our scale items: We avoided using ambiguous or unfamiliar terms, complicated syntax, or inconsistent questions (Podsakoff et al. 2003). Finally, we also employed the marker-variable technique (Podsakoff et al. 2003) and included a marker-variable (i.e., blue attitude) in our survey. The results showed that the average correlation between markervariable and the principal construct (i.e., continuance intention) was insignificant in the Amazon sample $(\beta=0.11, p>$ $0.05)$ and Etsy sample $(\beta=0.07, p>0.05)$. These procedures gave us confidence that common method bias is not a major concern in this study. 


\section{Analysis and results}

\section{Results of measurement model testing}

For our measurement model assessment, we examined all constructs regarding indicator loadings, internal consistency reliability, convergent validity and discriminant validity (Hair et al. 2019). First, the loadings of all indicators were above the recommended level of 0.70 , thus providing acceptable item reliability (see Appendix Table 4). Second, composite reliability and Cronbach's alpha of all constructs were considerably above the threshold of 0.70 , indicating a high internal consistency reliability. Third, average variance extracted of all constructs was above 0.50 , demonstrating adequate convergent validity. Lastly, discriminant validity is defined as the degree to which measures of different latent variables are unique (O'Leary-Kelly and Vokurka 1998) and can be tested using Heterotrait-Monotrait (HTMT) analysis. As shown in Appendix Table 5, all HTMT values were below the threshold of 0.80 (Hair et al. 2019). Therefore our constructs had acceptable discriminant validity.

\section{Results of hypothesis testing}

To test our hypotheses, we conducted hierarchical regression analysis with SPSS 27. The results of the hierarchical regression analysis, including standardized path coefficients and their statistical significance levels, are displayed in Fig. 2. We first tested for the effects of our control variables on the model's dependent variables. We did not find any significant effects of gender, age, education, country of residence, experience or number of offered products on sellers' continuance intentions (all $\mathrm{p}>0.05$ ).
The results ( $\mathrm{A}=$ Amazon; $\mathrm{E}=\mathrm{Etsy})$ showed that the model explained satisfactory variance in intrinsic motivation (A: 16.3\%; E: $19.2 \%$ ), perceived usefulness (A: $48.4 \%$; E: 36.7\%), satisfaction (A: 58.6\%; E: 46.2\%), and continuance intention (A: 56.1\%; E: $43.1 \%)$. Perceived input control had a negative significant effect on intrinsic motivation (A: $\beta=-0.16, p<0.01$; $\mathrm{E}$ : $\beta=$ $-0.23, \mathrm{p}<0.01$ ), supporting H1. Perceived clan control had a positive significant effect on intrinsic motivation (A: $\beta=0.35$, $p<0.001$; E: $\beta=0.33, \mathrm{p}<0.001$ ), supporting H2. Furthermore, we also found a positive significant effect of intrinsic motivation on perceived usefulness (A: $\beta=0.70, p<0.001 ; E$ : $\beta=0.75$, p $<0.001$ ) and on satisfaction (A: $\beta=0.76, p<0.001 ; \mathrm{E}: \beta=0.68$, $\mathrm{p}<0.001$ ), supporting H3a and H3b. Finally, our research model reconfirms the IS continuance model. The effects of perceived usefulness (A: $\beta=0.49, p<0.001 ; E: \beta=0.35, p<0.001)$ and satisfaction ( $A: \beta=0.32, p<0.001 ; E: \beta=0.36, p<0.001$ ) on continuance intention were both positive and significant.

We also tested the mediating role of intrinsic motivation using the PROCESS macro method (model 81) suggested by Hayes (Hayes 2013). As presented in Appendix Table 6, we used confidence intervals generated by bootstrapping (i.e., 5000 bootstrap samples generating $95 \%$ bias-corrected bootstrap confidence intervals) as criteria to check whether the indirect effects were significantly different from zero. First, we found that intrinsic motivation mediated the positive effect of perceived input control on sellers' perceived usefulness, satisfaction and subsequently continuance intention, supporting H4a. Second, we also found that intrinsic motivation mediated the negative effect of perceived clan control on sellers' perceived usefulness, satisfaction, and subsequently continuance intention, supporting $\mathrm{H} 4 \mathrm{~b}$.

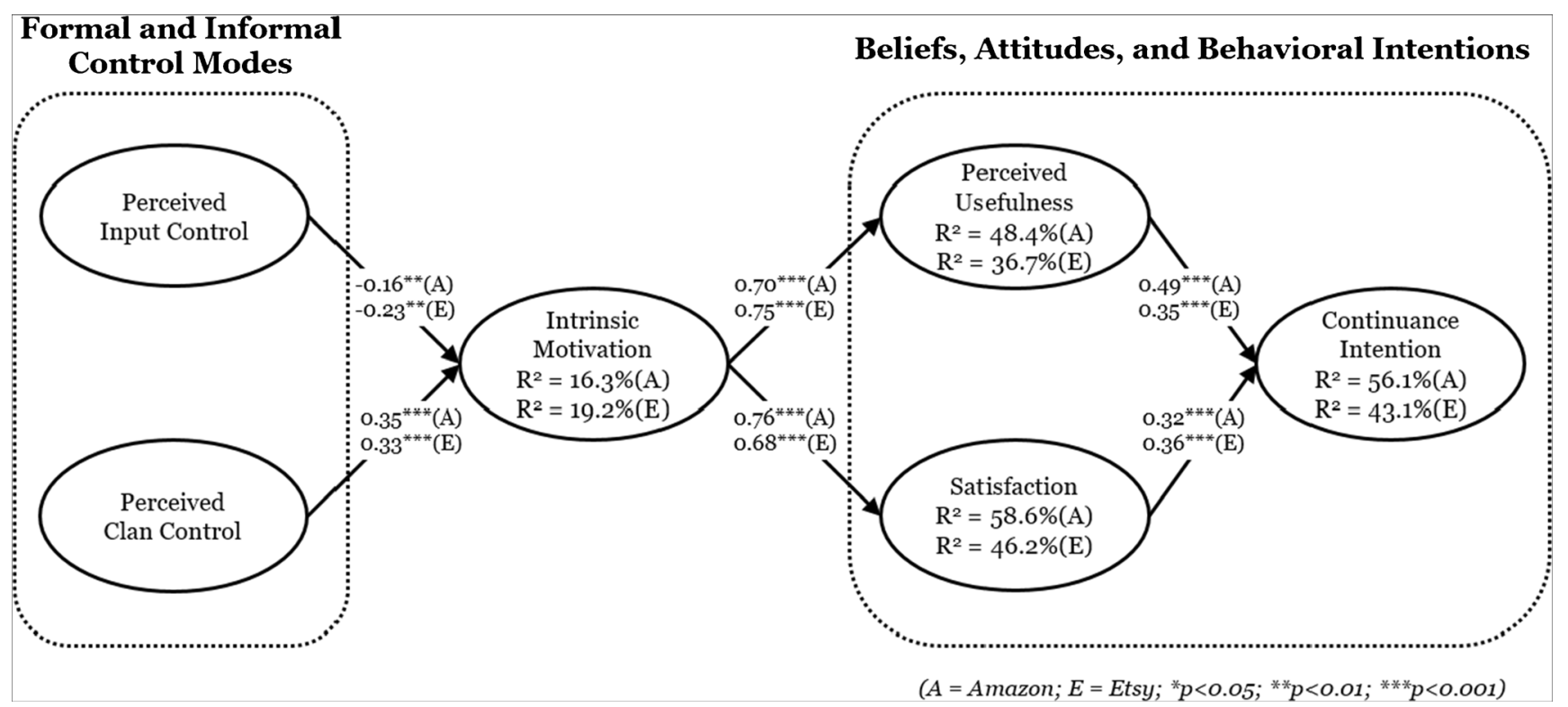

Fig. 2 Research results 
Lastly, we conducted between-group comparisons to identify potential differences between our two samples (i.e., Amazon and Etsy). As presented in Appendix Table 7, results of this analysis revealed significant differences in sellers' perceived input control, perceived clan control, intrinsic motivation, and satisfaction. In particular, our results confirmed the widely acknowledged difference in how control mechanisms are applied on both e-marketplace platforms (i.e., strict input control and loose clan control on Amazon/ loose input control and strict clan control on Etsy).

\section{Discussion}

IS research on e-marketplace platforms increasingly acknowledges the role of sellers in platforms' long-term viability and success. As such, examining how sellers perceive and react to control exercised by platform providers gains in importance. The main objective of this study was to investigate how and why perceived input control and perceived clan control affect sellers' beliefs, attitudes and behavioral intentions on e-marketplace platforms. To answer our research question, we collected survey data from Amazon $(n=286)$ and Etsy $(n=185)$, two of the largest emarketplace platforms with a different product portfolio focus. The two quantitative survey studies offer several key findings. First, we find that perceived input control reduces sellers' intrinsic motivation, as complying with requirements inhibits sellers' autonomy and freedom. Second, contrary to perceived input control, perceived clan control leads to higher intrinsic motivation, as sellers derive joy from the opportunity to engage with other sellers and to be part of the community. Third, intrinsic motivation enhances perceived usefulness, given that intrinsically motivated sellers process the available features of the emarketplace platform more thoroughly. Fourth, we find that intrinsic motivation leads to improved satisfaction with the emarketplace platform, reflecting the sensation of joy inherent to intrinsic motivation. Moreover, we successfully replicated the IS continuance model and were able to demonstrate a link between perceptions of both control modes and sellers' continuance intentions.

\section{Theoretical contributions}

Our study offers several important contributions to IS literature on e-marketplace platforms in general and on platform control in particular. First, by studying control modes on e-marketplace platforms, our work extends the research scope of increasing literature on platform control by the important and unique context of e-marketplace platforms (Hong et al. 2014; Johns 2006). Although prior studies have investigated effects of control modes in different platform contexts, such as mobile app platforms (Croitor and Benlian 2019; Goldbach and Benlian 2015a, 2015b; Goldbach et al. 2018), web-browser platforms (Croitor et al. 2020; Tiwana 2015), and crowdfunding platforms (Thies et al. 2018; Wessel et al. 2017), the effects of control modes on emarketplace platforms have been largely overlooked. As such, our paper responds to several research calls to investigate the effects of control modes in a thus far underexplored platform context (Croitor et al. 2020; Croitor and Benlian 2019; Goldbach et al. 2018; Wessel et al. 2017). More broadly, our insights are important beyond the context of e-marketplace platforms, as control is a critical and ubiquitous element of platform governance.

Second, by analyzing effects of both input control and clan control on digital platforms, our study extends prior research on platform control that has examined the effects of input control and clan control separately. To the best of our knowledge, our study is the first one to examine effects of input control and clan control on digital platforms in combination. In the context of emarketplace platforms, input control and clan control are particularly important for platform providers to align their interests with those of the sellers and have been highlighted in previous calls for research (Goldbach et al. 2018). To this end, we bring to light the opposing effects that perceived input control and perceived clan control exert on sellers' continuance intentions when sellers are subject to both types of control. As such, we additionally advance our understanding of the consequences of the two control modes input control and clan control.

A third contribution of this study relates to the explanation of why perceived input control and perceived clan control affect sellers' beliefs, attitudes and behavioral intentions. Only recently have studies started to unravel the explanatory mechanisms underlying the relationship between perceptions of control modes and behavioral intentions, thus far pointing at perceived autonomy as a mediator in complementors' continuance intentions (Goldbach et al. 2018). Our study extends knowledge on the underlying mechanisms that explain the relationship between perceptions of control and complementors' beliefs, attitudes and behavioral intentions. In particular, we find that intrinsic motivation mediates the relationship between perceptions of both input control and clan control and complementors' perceived usefulness, satisfaction and continuance intentions. We thus contribute to a more nuanced understanding of factors that explain complementors' intentions to stay on and keep contributing to digital platforms (Benlian et al. 2015).

\section{Practical implications}

Given that attracting and retaining sellers is becoming increasingly important (Galbreth et al. 2005; Sun 2010), our results also provide insightful implications for practitioners. For platform providers who are trying to attract and motivate sellers' to contribute to their e-marketplace platform or who are trying to sustain sellers' commitment, it is important to understand which types of control modes are likely to generate higher seller participation. Whereas input control deters sellers to continue using the 
platform, platform providers can harness clan control to free two birds with one key: align their interests and strategies with those of the sellers and increase the retention of sellers through greater intrinsic motivation, perceived usefulness and satisfaction. Therefore, we provide valuable guidance for platform providers how to best exercise control without hurting their objective of sustaining a large group of sellers.

\section{Limitations and future research directions}

This study should be interpreted in light of its limitations, which provide opportunities for future research. The first limitation is that we collected our data through a single survey design that captured both dependent and independent variables. Even though formal tests for common method bias in the results section indicated no substantial concern, future research could further validate our findings and thereby also confirm causality of our model through experimental research designs both in the lab as well as in the field.

While our study is, to the best of our knowledge, the first to investigate control modes on e-marketplace platforms, we call for research to extend our findings to other platforms and contexts. For example, future research may verify our propositions on emarketplace platforms with greater competition among sellers than observed on Amazon and Etsy, particularly to compare whether the positive effect of clan control remains. Furthermore, investigating input control and clan control in diverse platform contexts (e.g., accommodations, shops, games and crowdfunding) could advance the generalizability of our results. Moreover, future research may extend this study's model by including and comparing further types of control (e.g., self control, behavior control and output control) and further types of outcome (e.g., perceived performance), as well as by testing for additional mediators that could be conceptually related to control (e.g., perceived fairness and perceived effort).

We acknowledge that platform providers may consider sellers' continuance intentions as just one out of several objectives. Platform providers could also aim to maximize total platform sales volume, for example through enhancing competitiveness among sellers (Li et al. 2019). Imposing control, despite potential positive effects on sellers' continuance intentions, may hereby reduce sellers' performance and thus harm platform providers' objective, as first evidence in the case of clan control suggests (Zifla and Wattal 2019). As such, we urge future studies to investigate how different control modes affect the success of emarketplace platforms beyond sellers' continuance intentions.

The conceptual model was developed considering only negative effects of perceived input control. However, recent studies on platform governance pointed out potential positive effects of input control, such as increased knowledge sharing among platform participants (Zhang et al. 2020) as well as an improvement in their performance (Tiwana 2015; Wessel et al. 2017). Therefore, future research should extend and adapt our model to investigate both positive and negative effects of input control on sellers' continuance intentions on e-marketplace platforms.

Lastly, although our measurement scales were adopted from existing works, we recognize the potential threat of acquiescence bias (i.e., participants' tendency to agree with positively formulated items) (Billiet and McClendon 2000). We advise future research to replicate our study using balanced scales (Billiet and Davidov 2008), in which half of the items are framed negatively and half are framed positively.

Funding This research was funded by the German Research Foundation (DFG) under grant numbers BE 4308/3-1 and BE 4308/3-2. Open Access funding enabled and organized by Projekt DEAL.

\section{Appendix}

Table 1 Selected studies focusing on control modes on digital platforms

\begin{tabular}{|c|c|c|c|c|c|c|c|c|c|}
\hline \multirow[t]{2}{*}{ Platform context } & \multirow[t]{2}{*}{ Study } & \multicolumn{5}{|c|}{ Control modes } & \multicolumn{3}{|l|}{ Unit of analysis } \\
\hline & & Input & Behavior & Output & Clan & Self & Complementor & Complement & Platform \\
\hline \multirow{4}{*}{$\begin{array}{l}\text { Mobile app platforms } \\
\text { (e.g., Android and iOS) }\end{array}$} & (Goldbach and Benlian 2015a) & _- & - & - & $\mathrm{X}$ & _- & - & Performance & - \\
\hline & (Goldbach and Benlian 2015b) & - & - & - & $\mathrm{X}$ & $\mathrm{X}$ & Continuance intention & Quality & - \\
\hline & (Goldbach et al. 2018) & - & $\mathrm{X}$ & $\mathrm{X}$ & - & $\mathrm{X}$ & Continuance intention & Quality & - \\
\hline & (Croitor and Benlian 2019) & $\mathrm{X}$ & - & - & - & - & Continuance intention & - & - \\
\hline \multirow{2}{*}{$\begin{array}{l}\text { Web browser platforms } \\
\text { (e.g., Chrome and Firefox) }\end{array}$} & (Tiwana 2015) & $\mathrm{X}$ & - & - & - & - & - & Performance & - \\
\hline & (Croitor et al. 2020) & $\mathrm{X}$ & - & - & - & - & Continuance intention & - & - \\
\hline \multirow{3}{*}{$\begin{array}{l}\text { Crowdfunding platforms } \\
\text { (e.g., Kickstarter and Indiegogo) }\end{array}$} & (Wessel et al. 2017) & $\mathrm{X}$ & - & - & - & - & - & Success & Revenue \\
\hline & (Thies et al. 2018) & $\mathrm{X}$ & - & - & - & - & - & - & Network effects \\
\hline & (Croitor et al. 2021) & $\mathrm{X}$ & - & - & - & $\mathrm{X}$ & Continuance intention & - & - \\
\hline Gig Economy platforms (e.g., Uber) & (Cram et al. 2020) & $\mathrm{X}$ & $\mathrm{X}$ & $\mathrm{X}$ & - & - & Continuance intention & - & - \\
\hline $\begin{array}{l}\text { E-Marketplace platforms ( } \\
\text { e.g., Amazon and Etsy) }\end{array}$ & This study & $\mathrm{X}$ & - & - & $\mathrm{X}$ & - & Continuance intention & - & - \\
\hline
\end{tabular}


Table 2 Demographic distribution of the survey respondents

\begin{tabular}{llll}
\hline Variables & Category & Amazon $(\mathrm{n}=286)$ & Etsy $(n=185)$ \\
\hline \multirow{2}{*}{ Gender } & Female & 74 & 152 \\
Age & Male & 212 & 33 \\
& $18-24$ & 12 & 10 \\
& $25-34$ & 88 & 64 \\
& $35-44$ & 86 & 60 \\
& $45-54$ & 66 & 48 \\
Education & High school or below & 34 & 3 \\
& Bachelors & 73 & 70 \\
& Masters & 88 & 66 \\
Country of residence & Ph. D. & 113 & 42 \\
& Germany & 12 & 7 \\
& United States & 70 & 90 \\
Experience (offered products) & United Kingdom & 25 & 54 \\
& Other & 67 & 17 \\
& $1-5$ products & 17 & 7 \\
& $5-25$ products & 38 & 31 \\
& $25-100$ products & 38 & 70 \\
Experience (years) & $100-1000$ products & 103 & 70 \\
& $>1000$ products & 90 & 7 \\
& $<1$ year & 13 & 12 \\
& $1-2$ years & 41 & 22 \\
& $2-3$ years & 56 & 24 \\
& $3-4$ years & 30 & 45 \\
& $4-5$ years & 21 & 11 \\
& $>5$ years & 125 & 71 \\
\hline
\end{tabular}

Table 3 Construct measures

\begin{tabular}{|c|c|c|}
\hline Construct & Items & Source \\
\hline $\begin{array}{l}\text { Perceived Input Control } \\
\quad(\mathrm{PIC})\end{array}$ & $\begin{array}{l}\text { It is burdensome for me to comply with all requirements to be granted access to the } \\
\text { platform. } \\
\text { Overall, the platform sets strict formal criteria for access approval. } \\
\text { Getting access to the platform is subject to stringent screening processes. } \\
\text { In my opinion, it is hard to get access to the platform to sell my products. }\end{array}$ & $\begin{array}{l}\text { Adapted from Croitor and Benlian } \\
\text { (2019) }\end{array}$ \\
\hline $\begin{array}{l}\text { Perceived Clan Control } \\
\quad \text { (PCC) }\end{array}$ & $\begin{array}{l}\text { I attempt to be a regular member of the platform community. } \\
\text { I attempt to understand the platform's goals, values and norms. } \\
\text { I place a significant weight on understanding the platform's goals, values and norms. } \\
\text { I actively participate in seller forums, channels or groups to understand the platform's } \\
\text { goals, values and norms. }\end{array}$ & Adapted from Kirsch et al. (2002) \\
\hline $\begin{array}{l}\text { Intrinsic motivation } \\
\text { (IM) }\end{array}$ & $\begin{array}{l}\text { I enjoy selling my products on the platform. } \\
\text { I would describe selling products on the platform as very interesting. } \\
\text { Selling products on the platform is fun to do. }\end{array}$ & Adapted from Deci and Ryan (2002) \\
\hline $\begin{array}{l}\text { Perceived Usefulness } \\
\text { (PU) }\end{array}$ & $\begin{array}{l}\text { Using the platform improves my performance in selling products. } \\
\text { Using the platform increases my productivity in selling products. } \\
\text { Using the platform enhances my effectiveness in selling products. } \\
\text { Overall, the platform is useful for my business in selling products. }\end{array}$ & $\begin{array}{l}\text { Adapted from Agarwal and } \\
\text { Karahanna (2000) }\end{array}$ \\
\hline Satisfaction (SAT) & $\begin{array}{l}\text { My experience of selling products on the platform is very satisfied. } \\
\text { My experience of selling products on the platform is very pleased. } \\
\text { My experience of selling products on the platform is very contented. } \\
\text { My experience of selling products on the platform is very encouraged. }\end{array}$ & Adapted from Bhattacherjee (2001) \\
\hline $\begin{array}{l}\text { Continuance Intention } \\
\text { (CI) }\end{array}$ & $\begin{array}{l}\text { I expect my use of the platform for selling products to increase in the future. } \\
\text { I intend to continue using the platform for selling products in the future. } \\
\text { I plan to continue using the platform for selling products in the future. }\end{array}$ & Adapted from Bhattacherjee (2001) \\
\hline
\end{tabular}


Table 4 Results of the measurement model assessment (convergent validity)

\begin{tabular}{llllllll}
\hline Platform & Construct & Mean & S.D. & $\begin{array}{l}\text { Item } \\
\text { Loadings }\end{array}$ & $\begin{array}{l}\text { Composite } \\
\text { Reliability }\end{array}$ & $\begin{array}{l}\text { Cronbach's } \\
\text { Alpha }\end{array}$ & $\begin{array}{l}\text { Average Variance } \\
\text { Extracted }\end{array}$ \\
\hline \multirow{2}{*}{ Amazon } & PIC & 4.08 & 1.42 & $0.80-0.90$ & 0.92 & 0.88 & 0.74 \\
& PCC & 2.12 & 1.35 & $0.74-0.88$ & 0.87 & 0.80 & 0.62 \\
& IM & 4.02 & 1.27 & $0.73-0.91$ & 0.88 & 0.79 & 0.71 \\
& PU & 5.28 & 1.55 & $0.91-0.94$ & 0.95 & 0.92 & 0.85 \\
& SAT & 4.15 & 1.62 & $0.90-0.94$ & 0.95 & 0.92 & 0.90 \\
& CI & 5.39 & 1.64 & $0.90-0.93$ & 0.93 & 0.90 & 0.86 \\
& PIC & 1.91 & 1.04 & $0.79-0.90$ & 0.82 & 0.81 & 0.65 \\
& PCC & 4.55 & 1.39 & $0.77-0.86$ & 0.83 & 0.73 & 0.66 \\
& IM & 5.47 & 1.30 & $0.90-0.95$ & 0.93 & 0.91 & 0.86 \\
& PU & 5.27 & 1.62 & $0.89-0.94$ & 0.93 & 0.90 & 0.82 \\
& SAT & 4.65 & 1.65 & $0.90-0.95$ & 0.95 & 0.92 & 0.86 \\
& CI & 5.64 & 1.65 & $0.89-0.92$ & 0.92 & 0.90 & 0.88 \\
\hline
\end{tabular}

Table 5 Results of the measurement model assessment (discriminant validity)

\begin{tabular}{lllllll}
\hline Platform & Construct & PIC & PCC & IM & PU & SAT \\
\hline Amazon & PIC & & & & & \\
& PCC & 0.21 & & & & \\
& IM & 0.35 & 0.47 & & & \\
& PU & 0.29 & 0.36 & 0.70 & & \\
Etsy & SAT & 0.37 & 0.38 & 0.72 & 0.73 & \\
& CI & 0.28 & 0.32 & 0.66 & 0.66 & 0.65 \\
& PIC & & & & & \\
& PCC & 0.10 & & & & \\
& IM & 0.18 & 0.42 & & & \\
& PU & 0.18 & 0.39 & 0.69 & & \\
& SAT & 0.17 & 0.41 & 0.71 & 0.74 & \\
& CI & 0.10 & 0.39 & 0.66 & 0.71 & 0.70 \\
\hline
\end{tabular}


Table 6 Summary of mediation testing results

\begin{tabular}{lllllll}
\hline & Indirect effect path & Platform & Indirect effect & LLCI & ULCI & Mediation \\
\hline $\mathrm{H} 4 \mathrm{a}$ & $\mathrm{PIC} \rightarrow \mathrm{IM} \rightarrow \mathrm{PU} \rightarrow \mathrm{CI}$ & Amazon & -0.058 & -0.111 & -0.013 & Supported \\
& $\mathrm{PIC} \rightarrow \mathrm{IM} \rightarrow \mathrm{SAT} \rightarrow \mathrm{CI}$ & Etsy & -0.059 & -0.126 & -0.011 & \\
& & Amazon & -0.037 & -0.076 & -0.008 & \\
& & Etsy & -0.054 & -0.121 & -0.004 & \\
$\mathrm{H} 4 \mathrm{~b}$ & $\mathrm{PCC} \rightarrow \mathrm{IM} \rightarrow \mathrm{PU} \rightarrow \mathrm{CI}$ & Amazon & 0.131 & 0.075 & 0.199 & Supported \\
& & Etsy & 0.064 & 0.020 & 0.124 & \\
& $\mathrm{PCC} \rightarrow \mathrm{IM} \rightarrow \mathrm{SAT} \rightarrow \mathrm{CI}$ & Amazon & 0.084 & 0.037 & 0.144 & \\
& & Etsy & 0.059 & 0.006 & 0.119 & \\
\hline
\end{tabular}

Table 7 Between-group comparison of Amazon and Etsy

\begin{tabular}{|c|c|c|c|c|c|}
\hline Construct & Platform & Mean & S.D. & Mean difference & Significance \\
\hline \multirow[t]{2}{*}{ PIC } & Amazon & 4.08 & 1.42 & 2.17 & $* * *$ \\
\hline & Etsy & 1.91 & 1.04 & & \\
\hline \multirow[t]{2}{*}{ PCC } & Amazon & 2.12 & 1.35 & -2.43 & $* * *$ \\
\hline & Etsy & 4.55 & 1.39 & & \\
\hline \multirow[t]{2}{*}{ IM } & Amazon & 4.02 & 1.27 & -1.45 & $* * *$ \\
\hline & Etsy & 5.47 & 1.30 & & \\
\hline \multirow[t]{2}{*}{ PU } & Amazon & 5.28 & 1.55 & 0.01 & n.s. \\
\hline & Etsy & 5.27 & 1.62 & & \\
\hline \multirow[t]{2}{*}{ SAT } & Amazon & 4.15 & 1.62 & -0.50 & $* *$ \\
\hline & Etsy & 4.65 & 1.65 & & \\
\hline \multirow[t]{2}{*}{ CI } & Amazon & 5.39 & 1.64 & -0.25 & n.s. \\
\hline & Etsy & 5.64 & 1.65 & & \\
\hline
\end{tabular}

n.s. non-significant; $* p<0.05 ; * * p<0.01 ; * * * p<0.001$

Open Access This article is licensed under a Creative Commons Attribution 4.0 International License, which permits use, sharing, adaptation, distribution and reproduction in any medium or format, as long as you give appropriate credit to the original author(s) and the source, provide a link to the Creative Commons licence, and indicate if changes were made. The images or other third party material in this article are included in the article's Creative Commons licence, unless indicated otherwise in a credit line to the material. If material is not included in the article's Creative Commons licence and your intended use is not permitted by statutory regulation or exceeds the permitted use, you will need to obtain permission directly from the copyright holder. To view a copy of this licence, visit http://creativecommons.org/licenses/by/4.0/.

\section{References}

Agarwal, R., \& Karahanna, E. (2000). Time flies when you're having fun: Cognitive absorption and beliefs about information technology usage. MIS Quarterly, 24(4), 665-694. https://doi.org/10.2307/ 3250951

Amazon. (2020). Category, product, and listing restrictions. Retrieved from https://sellercentral.amazon.com/gp/help/external/G1801. Accessed 30 Aug 2020.
Ambrose, M. L., \& Kulik, C. T. (1999). Old friends, new faces: Motivation research in the 1990s. Journal of Management, 25(3), 231-292. https://doi.org/10.1016/S0149-2063(99)00003-3

Bagozzi, R. P., Gopinath, M., \& Nyer, P. U. (1999). The role of emotions in marketing. Journal of the Academy of Marketing Science, 27(2), 184-206.https://doi.org/10.1177/0092070399272005

Batra, R., \& Ray, M. L. (1986). Affective responses mediating acceptance of advertising. Journal of Consumer Research, 13(2), 234249. https://doi.org/10.1086/209063

Benlian, A., Hilkert, D., \& Hess, T. (2015). How open is this platform? The meaning and measurement of platform openness from the complementors' perspective. Journal of Information Technology, 30(3), 209-228.https://doi.org/10.1057/jit.2015.6

Bhattacherjee, A. (2001). Understanding information systems continuance: An expectation-confirmation model. MIS Quarterly, 25(3), 351-370. https://doi.org/10.2307/3250921

Billiet, J. B., \& Davidov, E. (2008). Testing the stability of an acquiescence style factor behind two interrelated substantive variables in a panel design. Sociological Methods \& Research, 36(4), 542562. https://doi.org/10.1177/0049124107313901

Billiet, J. B., \& McClendon, M. J. (2000). Modeling acquiescence in measurement models for two balanced sets of items. Structural Equation Modeling: A Multidisciplinary Journal, 7(4), 608628.https://doi.org/10.1207/S15328007SEM0704_5 
Boon, E., Pitt, L., \& Salehi-Sangari, E. (2015). Managing information sharing in online communities and marketplaces. Business Horizons, 58(3), 347-353. https://doi.org/10.1016/j.bushor.2015. 01.008

Boudreau, K. J. (2012). Let a thousand flowers bloom? An early look at large numbers of software app developers and patterns of innovation. Organization Science, 23(5), 1409-1427. https://doi.org/10. 1287/orsc. 1110.0678

Bourdieu, P., \& Nice, R. (1980). The production of belief - contribution to an economy of symbolic goods. Media, Culture and Society, 2(3), 261-293.

Cardinal, L. B. (2001). Technological innovation in the pharmaceutical industry: The use of organizational control in managing Research and Development. Organization Science, 12(1), 19-36.https://doi. org/10.1287/orsc.12.1.19.10119

Cardinal, L. B., Sitkin, S. B., \& Long, C. P. (2004). Balancing and rebalancing in the creation and evolution of organizational control. Organization Science, 15(4), 411-431. https://doi.org/10.1287/orsc. 1040.0084

Chua, C. E. H., Lim, W.-K., Soh, C., \& Sia, S. K. (2012). Enacting clan control in complex IT projects: A social capital perspective. MIS Quarterly, 36(2), 577-600. https://doi.org/10.2307/41703468

Constantinides, P., Henfridsson, O., \& Parker, G. G. (2018). Introduction - Platforms and infrastructures in the digital age. Information Systems Journal, 29(2), 381-400. https://doi.org/10.1287/isre. 2018.0794

Cram, A., Wiener, M., Tarafdar, M., \& Benlian, A. (2020). Algorithmic controls and their implications for gig worker wellbeing and behavior. International conference on information systems (ICIS), A Digital Conference.

Croitor, E., \& Benlian, A. (2019). Perceived input control on online platforms from the application developer perspective: Conceptualization and scale development. Journal of Decision Systems, 28(1), 19-40. https://doi.org/10.1080/12460125.2019. 1616977

Croitor, E., Adam, M., \& Benlian, A. (2020). Perceived input control on digital platforms: A mixed-methods investigation of web-browser platforms. Journal of Decision Systems, 30(1), 47-68. https://doi. org/10.1080/12460125.2020.1815440

Croitor, E., Werner, D., \& Benlian, A. (2021). The effects of control mechanisms on Complementors' behavioral intentions: An empirical study of reward-based Crowdfunding platforms. Hawaii international conference on computer systems (HICSS), A Digital Conference. https://doi.org/10.24251/HICSS.2021.745

Das, T. K., \& Teng, B.-S. (2001). Trust, control, and risk in strategic alliances: An integrated framework. Organization Studies, 22(2), 251-283. https://doi.org/10.1177/0170840601222004

Davis, F. D. (1989). Perceived usefulness, perceived ease of use, and user acceptance of information technology. MIS Quarterly, 13(3), 319 340. https://doi.org/10.2307/249008

de Reuver, M., Sørensen, C., \& Basole, R. C. (2018). The digital platform: A research agenda. Journal of Information Technology, 33(2), 124-135. https://doi.org/10.1057/s41265-016-0033-3

Deci, E. L., \& Ryan, R. M. (1985). Intrinsic motivation and selfdetermination in human behavior. New York: Plenum Press.

Deci, E. L., \& Ryan, R. M. (2002). Handbook of self-determination research. Rochester: University of Rochester Press.

Digitalcommerce. (2020). What are the top online marketplaces? Retrieved from https://www.digitalcommerce360.com/article/ infographic-top-online-marketplaces/. Accessed 30 Aug 2020.

Dinger, M., Thatcher, J., Treadway, D., Stepina, L., \& Breland, J. (2015). Does professionalism matter in the IT workforce? An empirical examination of IT professionals. Journal of the Association for Information Systems, 16(4), 281-313. https://doi.org/10.17705/ 1 jais.00392
Eisenmann, T., Parker, G., \& Van Alstyne, M. (2011). Platform envelopment. Strategic Management Journal, 32(12), 1270-1285. https:// doi.org/10.1002/smj.935

Etsy. (2020). Seller Policy. Retrieved from https://www.etsy.com/legal/ sellers/. Accessed 30 Aug 2020

Foerderer, J., Kude, T., Schuetz, S. W., \& Heinzl, A. (2018). Knowledge boundaries in enterprise software platform development: Antecedents and consequences for platform governance. Information Systems Journal, 29(1), 119-144. https://oi.org/10. 1111/isj. 12186

Gagné, M., \& Deci, E. L. (2005). Self-determination theory and work motivation. Journal of Organizational Behavior, 26(4), 331362. https://doi.org/10.1002/job.322

Galbreth, M. R., March, S. T., Scudder, G. D., \& Shor, M. (2005). A game-theoretic model of E-marketplace participation growth. Journal of Management Information Systems, 22(1), 295319. https://doi.org/10.1080/07421222.2003.11045837

Goldbach, T., \& Benlian, A. (2015a). How social capital facilitates clan control on software platforms to enhance app-Developers' performance and success. Proceedings of the 36th international conference on information systems (ICIS), Fort Worth, Texas, USA.

Goldbach, T., \& Benlian, A. (2015b). Understanding informal control modes on software platforms - the mediating role of third-party Developers' intrinsic motivation. Proceedings of the 36th international conference on information systems (ICIS), Fort Worth, Texas, USA.

Goldbach, T., Benlian, A., \& Buxmann, P. (2018). Differential effects of formal and self-control in mobile platform ecosystems: Multimethod findings on third-party developers' continuance intentions and application quality. Information \& Management, 55(3), 271284. hhttps://doi.org/10.1016/j.im.2017.07.003

Gopal, A., \& Gosain, S. (2010). Research note - the role of organizational controls and boundary spanning in software development outsourcing: Implications for project performance. Information Systems Research, 21(4), 960-982. https://doi.org/10.1287/isre. 1080.0205

Hagiu, A. (2006). Pricing and commitment by two-sided platforms. The Rand Journal of Economics, 37(3), 720-737. https://doi.org/10. 1111/j.1756-2171.2006.tb00039.x

Hagiu, A., \& Yoffie, D. B. (2009). What's your Google strategy? Harvard Business Review, 87(4), 74-81.

Hair, F., Risher, J., Sarstedt, M., \& Ringle, C. (2019). When to use and how to report the results of PLS-SEM. European Business Review, 31(1), 2-24. https://doi.org/10.1108/EBR-11-2018-0203

Hall, R. H. (1968). Professionalization and bureaucratization. American Sociological Review, 33(1), 92-104. https://www.jstor.org/stable/ 2092242

Hayes, A. F. (2013). Introduction to mediation, moderation, and conditional process analysis: A regression-based approach. New York: Guilford Publications.

Hilkert, D., Benlian, A., \& Hess, T. (2010). Motivational drivers to develop apps for social software-platforms: The example of Facebook. Proceedings of the 16th Americas conference on information systems (AMCIS), Lima, Peru.

Ho, C.-H. (2010). Continuance intention of e-learning platform: Toward an integrated model. International Journal of Electronic Business Management, 8(3), 207-215.

Hong, W., Chan, F. K. Y., Thong, J. Y. L., Chasalow, L. C., \& Dhillon, G. (2014). A framework and guidelines for context-specific theorizing in information systems research. Information Systems Research, 25(1), 111-136. https://doi.org/10.1287/isre.2013.0501

Huang, J., Henfridsson, O., Liu, M. J., \& Newell, S. (2017). Growing on steroids: Rapidly scaling the User Base of digital ventures through digital innovation. MIS Quarterly, 41(1), 301-314. https://doi.org/ 10.25300/MISQ/2017/41.1.16 
Igbaria, M., \& Chidambaram, L. (1997). The impact of gender on career success of information systems professionals: A human-capital perspective. Information Technology \& People, 10(1), 63-86. https:// doi.org/10.1108/09593849710166165

Johns, G. (2006). The essential impact of context on organizational behavior. The Academy of Management Review, 31(2), 386408. https://doi.org/10.5465/amr.2006.20208687

Katz, M. L., \& Shapiro, C. (1985). Network externalities, competition, and compatibility. The American Economic Review, 75(3), 424 440 .

Kaufmann, N., Schulze, T., \& Veit, D. (2011). More than fun and money. Worker Motivation in Crowdsourcing-A Study on Mechanical Turk. Proceedings of the 17th Americas conference on information systems (AMCIS), Detroit, Michigan, USA.

Kim, H. J., Kim, I., \& Lee, H. (2016). Third-party mobile app developers' continued participation in platform-centric ecosystems: An empirical investigation of two different mechanisms. International Journal of Information Management, 36(1), 44-59.https://doi.org/10.1016/j. ijinfomgt.2015.09.002

Kirsch, L. J. (1996). The Management of Complex Tasks in organizations: Controlling the systems development process. Organization Science, 7(1), 1-21. https://doi.org/10.1287/orsc.7.1.1

Kirsch, L. J. (1997). Portfolios of control modes and IS Project Management. Information Systems Research, 8(3), 215 239. https://doi.org/10.1287/isre.8.3.215

Kirsch, L. J. (2004). Deploying common systems globally: The dynamics of control. Information Systems Research, 15(4), 374-395. https:// doi.org/10.1287/isre.1040.0036

Kirsch, L. J., Sambamurthy, V., Ko, D. G., \& Purvis, R. L. (2002). Controlling information systems development projects: The view from the client. Management Science, 48(4), 484-498. https://doi. org/10.1287/mnsc.48.4.484.204

Kohli, R., \& Kettinger, W. J. (2004). Informating the clan: Controlling Physicians' costs and outcomes. MIS Quarterly, 28(3), 363394. https://doi.org/10.2307/25148644

Li, H., Fang, Y., Lim, K. H., \& Wang, Y. (2019). Platform-based function repertoire, reputation, and sales performance of E-marketplace sellers. MIS Quarterly, 43(1), 207-236. https://doi.org/10.25300/ MISQ/2019/14201

Mano, H. (1992). Judgments under distress: Assessing the role of unpleasantness and arousal in judgment formation. Organizational Behavior and Human Decision Processes, 52(2), 216-245. https:// doi.org/10.1016/0749-5978(92)90036-7

MarketplacePulse. (2020). Number of Sellers on Amazon Marketplace. Retrieved from https://www.marketplacepulse.com/amazon/ number-of-sellers

McIntyre, D. P., \& Srinivasan, A. (2017). Networks, platforms, and strategy: Emerging views and next steps. Strategic Management Journal, 38(1), 141-160. https://doi.org/10.1002/smj.2596

O'Leary-Kelly, S. W., \& Vokurka, R. J. (1998). The empirical assessment of construct validity. Journal of Operations Management, 16(4), 387-405. https://doi.org/10.1016/S0272-6963(98)00020-5

Oliver, R. L. (1980). A cognitive model of the antecedents and consequences of satisfaction decisions. Journal of Marketing Research, 17(4), 460-469. https://doi.org/10.1177/002224378001700405

Ouchi, W. G. (1979). A conceptual framework for the design of organizational control mechanisms. Management Science, 25(9), 833848. https://doi.org/10.1287/mnsc.25.9.833

Ouchi, W. G. (1980). Markets, bureaucracies, and clans. Administrative Science Quarterly, 25(1), 129-141. https://doi.org/10.2307/ 2392231

Ouchi, W. G., \& Price, R. L. (1978). Hierarchies, clans, and theory Z: A new perspective on organization development. Organizational Dynamics, 7(2), 25-44. https://doi.org/10.1016/0090-2616(78) 90036-0
Podsakoff, P. M., MacKenzie, S. B., Lee, J.-Y., \& Podsakoff, N. P. (2003). Common method biases in behavioral research: A critical review of the literature and recommended remedies. Journal of Applied Psychology, 88(5), 879-903. https://doi.org/10.1037/ 0021-9010.88.5.879

Rode, H. (2016). To share or not to share: The effects of extrinsic and intrinsic motivations on knowledge-sharing in Enterprise social media platforms. Journal of Information Technology, 31(2), 152165.https://doi.org/10.1057/jit.2016.8

Ryan, R. M., \& Deci, E. L. (2000). Self-determination theory and the facilitation of intrinsic motivation, social development, and wellbeing. American Psychologist, 55(1), 68-78. https://doi.org/10. 1037/0003-066X.55.1.68

Saunders, C., Benlian, A., Henfridsson, O., \& Wiener, M. (2020). IS control and governance. In A. Bush \& A. Rai (Eds.), MIS Quarterly Research Curations. Retrieved from https:// www.misqresearchcurations.org/blog/2020/11/23/is-control-ampgovernance

Securities and Exchange Commission. (2019). Etsy: Integrated annual report. (Commission File Number 001-36911), United States Securities and Exchange Commission, Washington, D.C. https:// s22.q4cdn.com/941741262/files/doc_financials/annual/2019/EtsyAnnual-Report.pdf

Sheldon K. M., Turban D. B., Brown K. G., Barrick M. R., \& Judge T. A. (2003). Applying self-determination theory to organizational research. In: M. Buckley, J. Halbesleben \& A. R. Wheeler (Eds.) Research in Personnel and Human Resources Management, 22, 357-393. Emerald Group Publishing Limited. https://doi.org/10.1016/S0742-7301(03)22008-9

Song, P., Xue, L., Rai, A., \& Zhang, C. (2018). The ecosystem of software platform: A study of asymmetric cross-side network effects and platform governance. MIS Quarterly, 42(1), 121-142.https:// doi.org/10.25300/MISQ/2018/13737

Sun, H. (2010). Sellers' trust and continued use of online marketplaces. Journal of the Association for Information Systems, 11(4), 182-211. https://doi.org/10.17705/1jais.00226

Sun, H., Fan, M., \& Tan, Y. (2020). An empirical analysis of seller advertising strategies in an online marketplace. Information Systems Research, 31(1), 37-56. https://doi.org/10.1287/isre.2019. 0874

Tan, B., Pan, S., Lu, X., \& Huang, L. (2015). The role of IS capabilities in the development of multi-sided platforms: The digital ecosystem strategy of https://www.Alibaba.com. Journal of the Association for Information Systems, 16(4), 248-280. https://doi.org/10.17705/ 1jais.00393

Thatcher, J., Dinger, M., \& George, J. F. (2012). Information technology worker recruitment: An empirical examination of entry-level IT job seekers' labor market. Communications of the Association for Information Systems, 31(1), 1-34.https://doi.org/10.17705/1CAIS. 03101

Thies, F., Wessel, M., \& Benlian, A. (2016). Effects of social interaction dynamics on platforms. Journal of Management Information Systems, 33(3), 843-873.https://doi.org/10.1080/07421222.2016. 1243967

Thies, F., Wessel, M., \& Benlian, A. (2018). Network effects on crowdfunding platforms: Exploring the implications of relaxing input control. Information Systems Journal, 28(6), 1239-1262.https:// doi.org/10.1111/isj.12194

Tiwana, A. (2015). Evolutionary competition in platform ecosystems. Information Systems Research, 26(2), 266-281.https://doi.org/10. 1287/isre.2015.0573

Tiwana, A., Konsynski, B., \& Bush, A. A. (2010). Platform evolution: Coevolution of platform architecture, governance, and environmental dynamics. Information Systems Research, 21(4), 675687. https://doi.org/10.1287/isre.1100.0323 
Venkatesh, V., Speier, C., \& Morris, M. G. (2002). User acceptance enablers in individual decision making about technology: Toward an integrated model. Decision Sciences, 33(2), 297-316. https://doi. org/10.1111/j.1540-5915.2002.tb01646.x

Wareham, J., Fox, P. B., \& Giner, J. L. C. (2014). Technology ecosystem governance. Organization Science, 25(4), 1195-1215. https://doi. org/10.1287/orsc.2014.0895

Wessel, M., Thies, F., \& Benlian, A. (2017). Opening the floodgates: The implications of increasing platform openness in crowdfunding. Journal of Information Technology, 32(4), 344-360.https://oi. org/10.1057/s41265-017-0040-z

Wiener, M., Mähring, M., Remus, U., \& Saunders, C. (2016). Control configuration and control enactment in information systems projects: Review and expanded theoretical framework. MIS Quarterly, 40(3), 741-774. https://doi.org/10.25300/MISQ/2016/ 40.3.11

Wiener, M., Mahring, M., Remus, U., Saunders, C., \& Cram, W. A. (2019). Moving IS project control research into the digital era: The "why" of control and the concept of control purpose. Information
Systems Research, 30(4), 1387-1401.https://doi.org/10.1287/isre. 2019.0867

Zhang, Y., Li, J., \& Tong, T. W. (2020). Platform governance matters: How platform gatekeeping affects knowledge sharing among complementors. Strategic Management Journal, 1-28. https://doi. org/10.1002/smj.3191

Zheng, H., Li, D., \& Hou, W. (2011). Task design, motivation, and participation in crowdsourcing contests. International Journal of Electronic Commerce, 15(4), 57-88.https://doi.org/10.2753/ JEC1086-4415150402

Zifla, E., \& Wattal, S. (2019). Understanding IT-enabled social features in online peer-to-peer businesses for cultural goods. Journal of the Association for Information Systems, 20(5), 629-646. https://doi. org/10.17705/1jais.00546

Publisher's note Springer Nature remains neutral with regard to jurisdictional claims in published maps and institutional affiliations. 